\title{
NUMERICAL MODELLING OF PITTING CORROSION IN RC STRUCTURES
}

\section{ELIASS EL ALAMI', FATIMA-EZZAHRA FEKAKํㅜ, LUIGI GARIBALDI² AND AHMED EL KHALFI ${ }^{1}$}

\author{
${ }^{1}$ Laboratoire de mécanique, Université Sidi Mohamed Ben Abdellah, Fez, Morocco \\ ${ }^{2}$ Dipartimento di Ingegneria Meccanica e Aerospaziale, Politecnico di Torino, Torino, Italy
}

Key words: Non-uniform corrosion, RC structures, Finite element method, Contact steelconcrete, Damage plasticity, Crack propagation.

\begin{abstract}
Summary
During its life expectancy, a RC structure is exposed to corrosion. This phenomenon attacks the reinforcement and lead to the creation of a third material that is rust, at the expense of steel. This corrosion material takes more volume than the lost volume of steel and generates internal stresses that lead to the deterioration of the steel-concrete interface and to the cracking of the concrete cover. The distribution of the rust around the reinforcement for a natural corrosion is non-uniform and irregular. This distribution is associated to corrosion "pits" that are localized and concentrated in the regions exposed to corrosion. To better study and understand the phenomenon of pitting corrosion, a 2D numerical model is adopted. This model associates the corrosion of the reinforcement to a single pit, located at the top of the rebar. A model that take into account the damaging of the concrete in compression and tension is used and an interface between the two materials that models a tangential and normal contact is adopted.
\end{abstract}

\section{INTRODUCTION}

The corrosion of rebars is inevitable for RC structures. Their life expectancy, generally about 50 years, depend on the agressivity of the environment where the structure is located. Corrosion can be caused by the deposition of chlorides on the surface of the concrete cover, and because of its porous nature, chlorides penetrate the cover and reach the rebar. They react with the steel of the reinforcement and generate in the corroded zones a third material that is rust. This accumulation of chlorides leads to development of corrosion pits. These pits represent the localized attack of chloride. Their distribution is irregular along the rebar and is concentrated in the most exposed zones to the aggressive environment [1]. The rust accumulated in these corrosion pits, mainly composed of water, takes more volume than the lost steel. This leads to development of internal stresses in the concrete that generates cracks in the cover concrete and damages the interface between steel and concrete. The purpose of this study is to develop a 2D numerical model of a corroded beam with a single rebar. The corrosion is represented with a single pit that gets larger with the increase of the corrosion level. Two aspects are studied, the first one concerns the damaging of the concrete cover in compression and tension caused by the volume expansion of the rebar. The second aspect concerns the evolution and the deterioration of the interface between the concrete and the rebar due to this exact same volume expansion. 


\section{MODEL DESCRIPTION}

\subsection{Presentation of the model geometry}

We consider in this study 2D model representing the cross section of beam with a small reinforcement. The dimensions of the beam are $100 \times 100 \mathrm{~mm}$ and the diameter of the rebar is $10 \mathrm{~mm}$. The pitting corrosion model of Melcher and Val [2] is adopted in this paper to simulate to process of corrosion. This model, represented in figure 1, associates the non-uniform distribution of rust around the rebar to a single pit located at the top of the reinforcement.

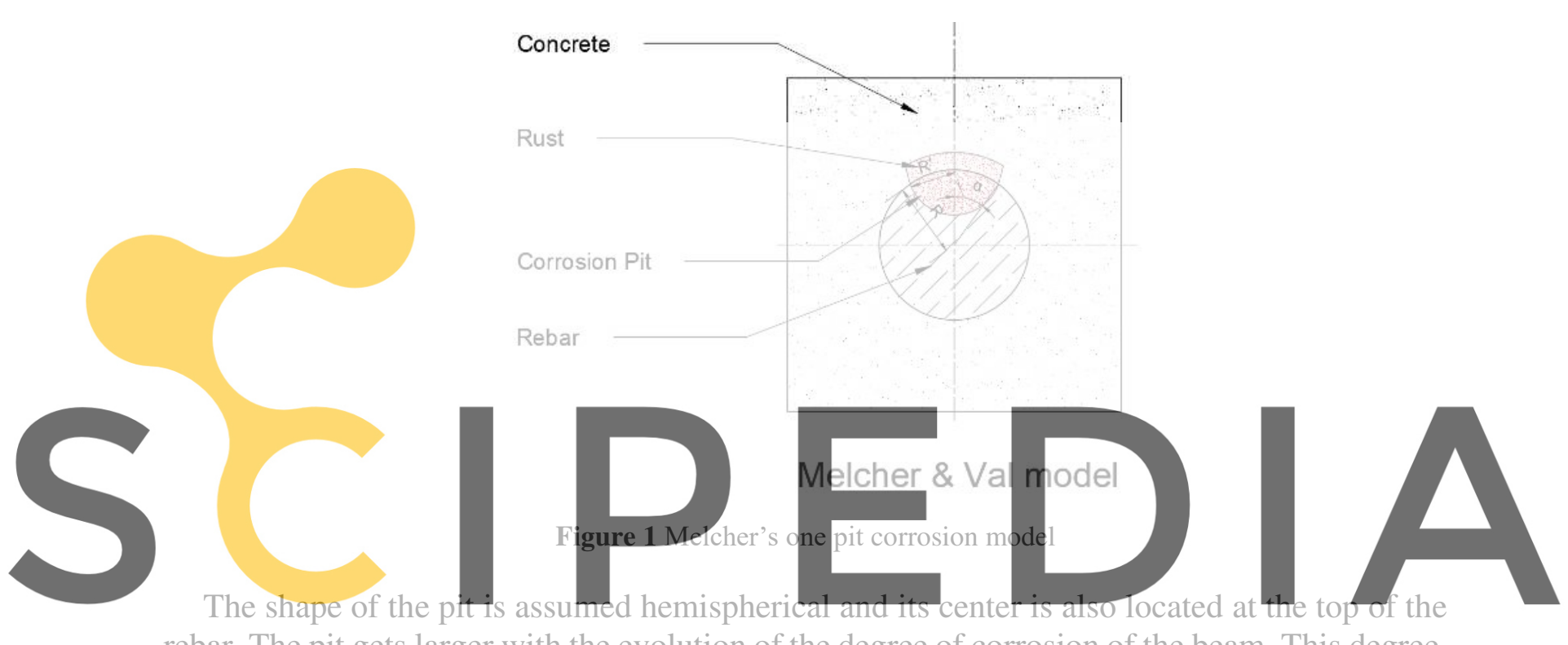

rebar. The pit gets larger with the evolution of the degree of corrosion of the beam. This degree,

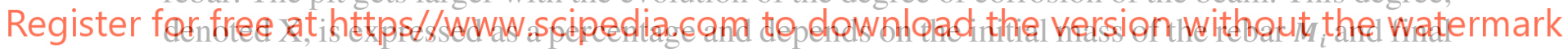

mass of the rebar $M_{f}$ of which we removed the rust. Assuming that the shape of the pit is

hemispherical allows us to calculate its surface. We also assume that the density of the rust is the same as the density of the steel and because we have a $2 \mathrm{D}$ model, we get the following equation:

$$
X=\frac{M_{i}-M_{f}}{M_{i}}=\frac{A}{A_{\text {rebar }}}
$$

where A the surface of the pit and $\boldsymbol{A}_{\text {rebar }}$ the surface of the rebar. We also calculate the surface of the pit depending on $\mathrm{R}$ the radius of the rebar, $\mathrm{R}$ ' the radius of the pit and $\alpha$ the angle of the pit. We have the following equation:

$$
X A_{\text {rebar }}=2 \pi \cdot\left(\frac{R^{\prime 2}}{360} \cdot\left(90-\sin ^{-1}\left(\frac{R^{\prime}}{R}\right)\right)+\frac{R^{2}}{360} \cdot \sin ^{-1}\left(\frac{R^{\prime}}{R}\right)\right)-R^{\prime} .\left(\sqrt{R^{2}-R^{\prime 2}}-\left(R-\sqrt{R^{2}-R^{\prime 2}}\right)\right)
$$


According to the equations (1) and (2) we can determine the radius of the pit in function of the size of the rebar and the degree of corrosion of the reinforcement.

\subsection{Presentation of materials models and the concrete-steel interface}

We used for this numerical study the commercial software ABAQUS that offers a Concrete Damage Plasticity model (CDP model) for the concrete that models two mechanisms that are compression crushing and tension cracking. This model suits the simulation because the volume expansion of the rebar damages in compression the concrete at the interface and in tension the concrete cover leading to the development of cracks. This damaging of the material affects the initial elastic modulus $E_{0}$ using a damage parameter $\mathrm{d}$ as presented in the following formula:

$$
E=(1-d) E_{0}
$$

where $\mathrm{E}$ the elastic modulus of the damaged material. Several laboratory tests are necessary to identify all the parameters of the CDP model. These tests were conducted by Jankowiak et al. [3] and the CDP parameters are presented in table 1. Figure 2 presents the tension damaging of the concrete using the Jankowiak et al. [3] model.

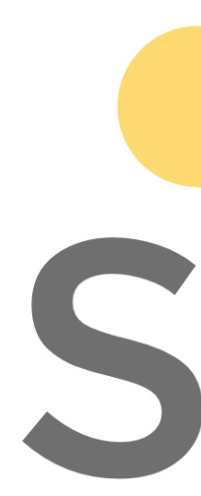

Table 1: CDP Model parameters [3]

CDP Parameters
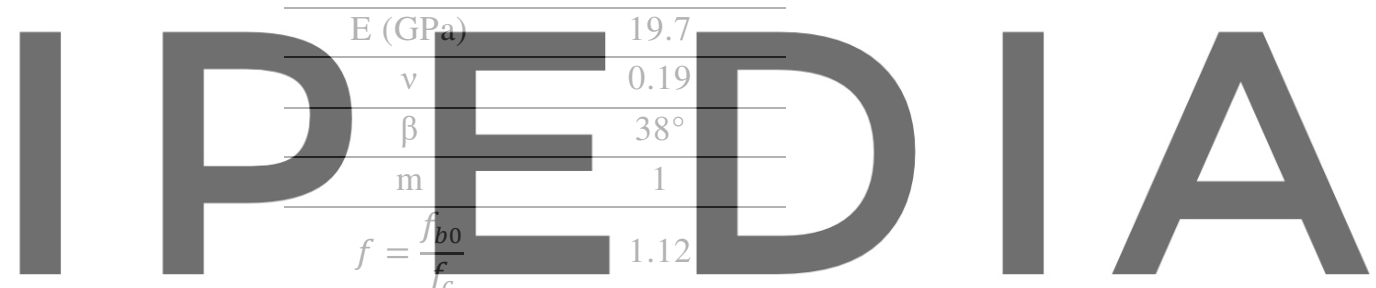

Register for free at https//www.scipedia.com to download the version without the watermark

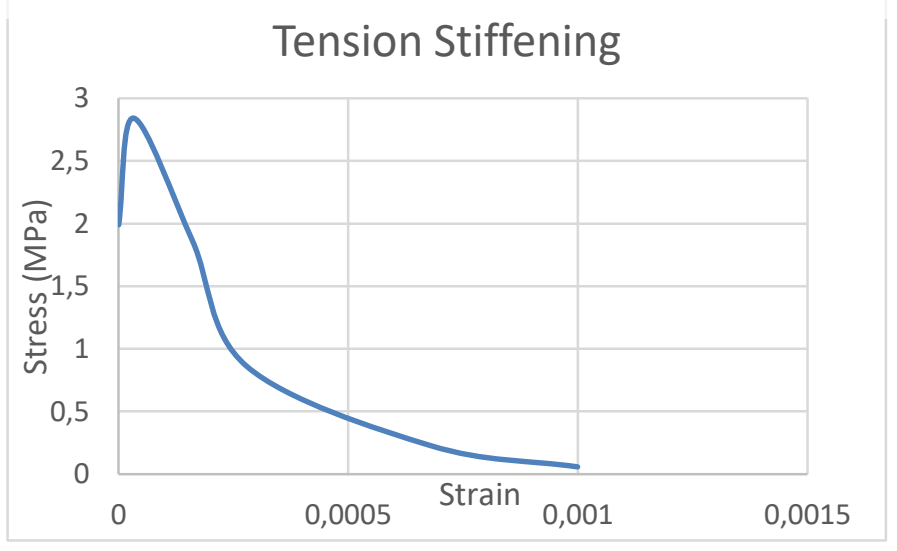

Figure 2 Tensile stiffening of the concrete

The rebar is modeled using a classic elastic model and the parameters are presented in table 2 
Table 2: Rebar elastic parameters

\begin{tabular}{cc}
\hline \multicolumn{2}{c}{ Rebar elastic properties } \\
\hline $\mathrm{E}(\mathrm{GPa})$ & 210 \\
\hline$v$ & 0.2 \\
\hline
\end{tabular}

The concrete-steel interface was modeled using the "Interaction" module of ABAQUS. The interface is set to have no gap between the two materials at the start of the study and models the normal and tangential contact that may occur during the corrosion process. The interface is able to assess the bond stress and normal pressure between the concrete and the rebar.

\subsection{Rust distribution}

The volume expansion is modeled with a radial displacement imposed on the nodes of the rebar. The distribution of the rust on top of the pit is chosen to have a Gaussian shape as it is shown in figure 1. The displacement distribution follows the equation below:

$$
d_{p}=A_{m} \cdot \cos \frac{2 \pi y}{C}
$$

with $d_{p}$ the displacement, $A_{m}$ the amplitude, $\mathrm{C}$ a parameter that depends on the size of the pit and $y$ the position following the y-axis of the node. The condition of a displacement equal to 0 for the first and the last node of the pit region is enforced.

\section{RESULTS}

In our work, we stud the concrete cover and t
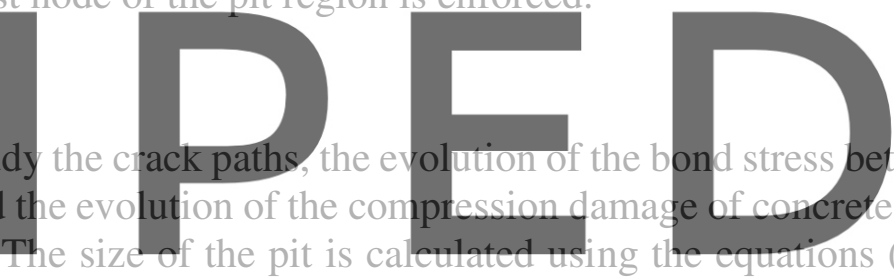
a $4 \%$ corroded rebar. volume expansion expressed in terms of a displacement is set to vary from 0 to $117 \mu \mathrm{m}$. Figure

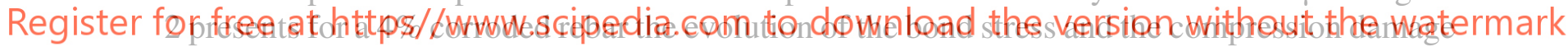
in function of the volume expansion at the pit concrete-steel interface.

Corrosion level : $4 \%$

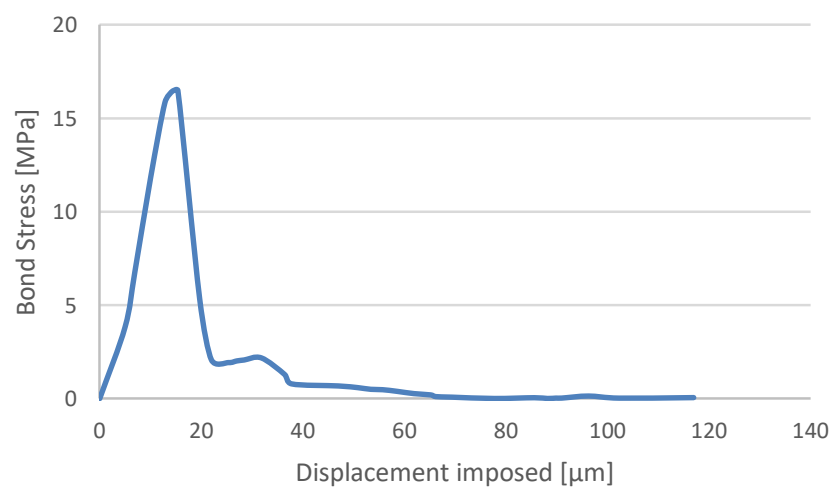




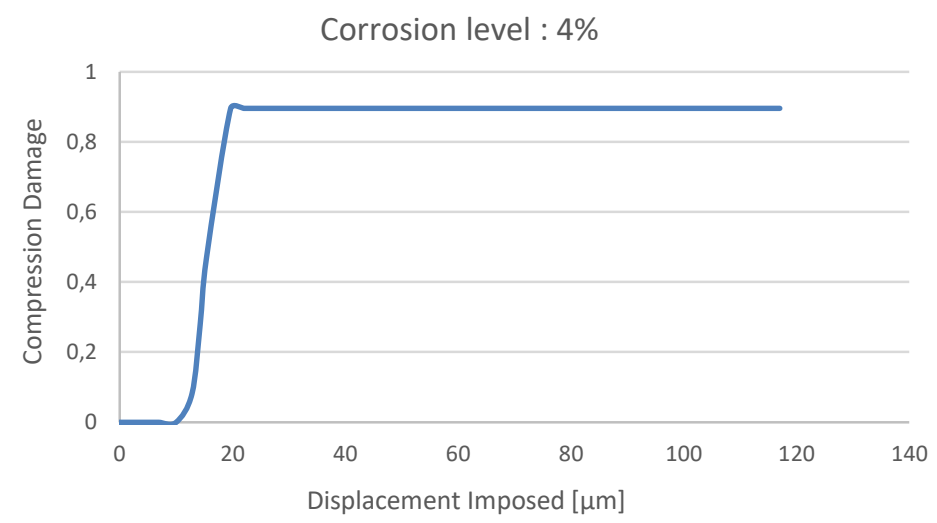

Figure 3 Evolution of the bond stress and compression damage in function of the imposed displacement

We notice that the evolution of the compression damage of the concrete impact directly the evolution of bond stress at the interface. Damaging the concrete at the interface leads to the deterioration of the bond stress between the reinforcement and the rebar. Similar results are found and presented in [4].

We present in the figure 3 the crack paths obtained for a $4 \%$ corroded rebar with an imposed displacement of $117 \mu \mathrm{m}$. Similar crack paths are obtained experimentally and numerically in [5].
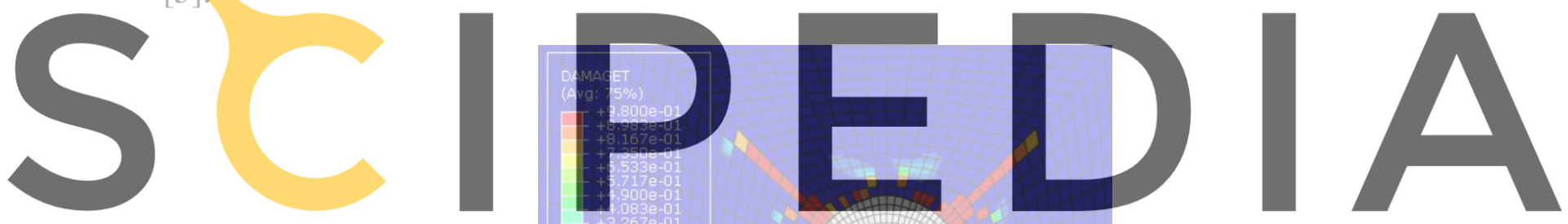

Register for free at https//www.scipedia.com to download the version without the watermark

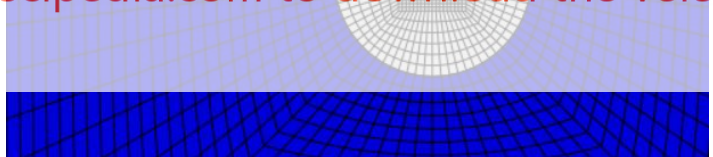

Figure 4 Crack paths of a $4 \%$ corroded rebar with a imposed displacement of $117 \mu \mathrm{m}$

\section{CONCLUSION}

This model allows us to study the impact of pitting corrosion on a RC structure. The model takes into account the damaging in compression and tension of the concrete and an interface between the two materials is modeled. A link between the compression damage of the concrete and the decrease of the bond stress and the corroded interface appears and crack paths in the concrete cover are obtained. The development of this model for other degrees of corrosion will help to understand the impact of pitting corrosion on RC structure. We are extending this numerical approach to a 3D bar in order to fully study a RC structures.

\section{REFERENCES}

[1] Zhu, W., François, R., \& Liu, Y. (2017). Propagation of corrosion and corrosion patterns of 
bars embedded in RC beams stored in chloride environment for various periods. Construction and Building Materials, 145, 147-156.

[2] Melchers\&Vals. (1997). Reliability of deteriorating RC Slab bridge. (1993), 1638-1644.

[3] Jankowiak, T., \& Łodygowski, T. (2005). Identifcation of parameters of concrete damage plasticity constitutive model. Foundations of Civil and Environmental Engineering, 6, 5369.

[4] Tepfers, R. (1979). Cracking Of Concrete Cover Along Anchored Deformed Reinforcing Bars. Magazine of Concrete Research, 31(106), 3-12.

[5] Thybo, A. E. A., Michel, A., \&Stang, H. (2017). Smeared crack modelling approach for corrosion-induced concrete damage. Materials and Structures/Materiaux et Constructions, $50(2)$.
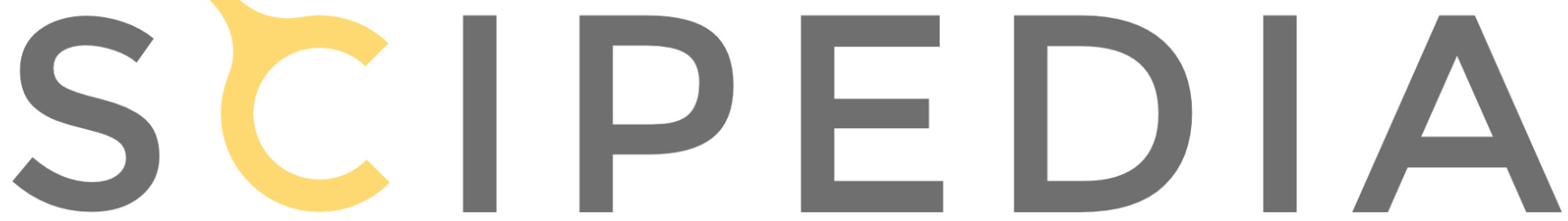

Register for free at https//www.scipedia.com to download the version without the watermark 